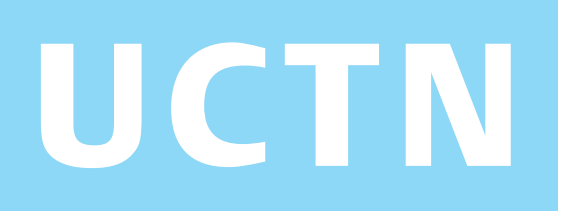

\title{
Comparison of commercial and custom-made EUS balloons: technical and clinical evaluation
}
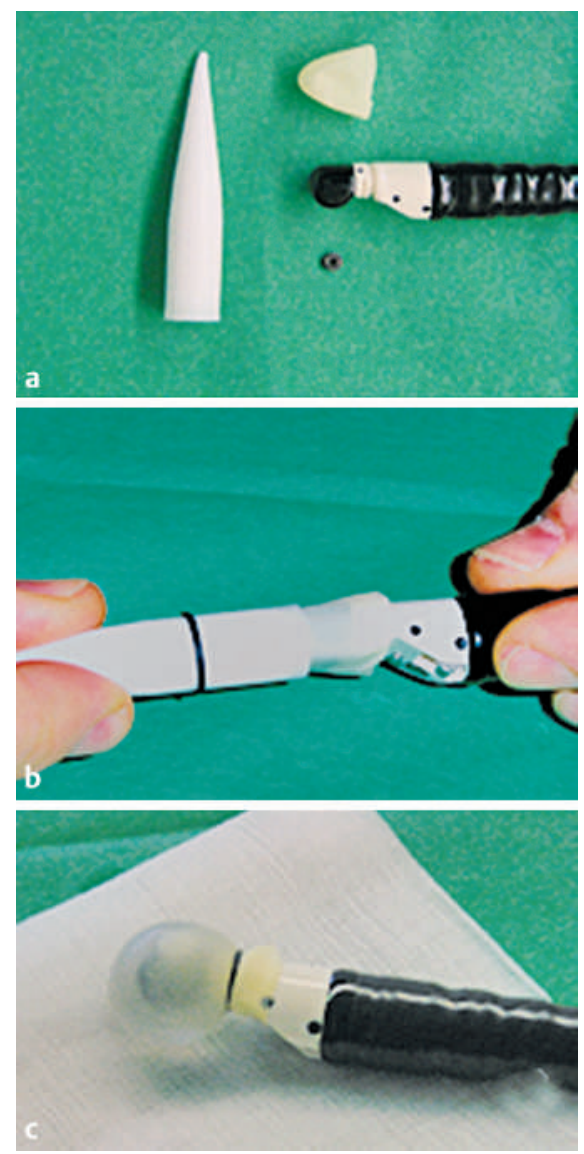

Figure 1 The glove finger ends (the small finger of a small latex examination glove; Dermaclean, Ansel, Bangkok, Thailand) were cut to a length of approximately $1.5 \mathrm{~cm}$. a After being positioned on the ultrasound head, the balloon was attached with the aid of a Hämolastik rubber band (Pauldrach, Garbsen, Germany) in the balloon-positioning ridge. $\mathbf{b}$ The rubber band was placed under tension before application, with the aid of a conical applicator. c The inflated balloon.

Commercial balloons make a significant contribution to the running costs of endoscopic ultrasonography (EUS) units. We compared 10 commercially available EUS balloons for the Olympus GF-UMT140 (Olympus Optical, Hamburg, Germany) with 20 latex balloons made of latex glove fingers and attached with rubber ligature bands (Figure $\mathbf{1}$ ).

The two types were compared with regard to the time needed to position the balloon, the time required to inflate the
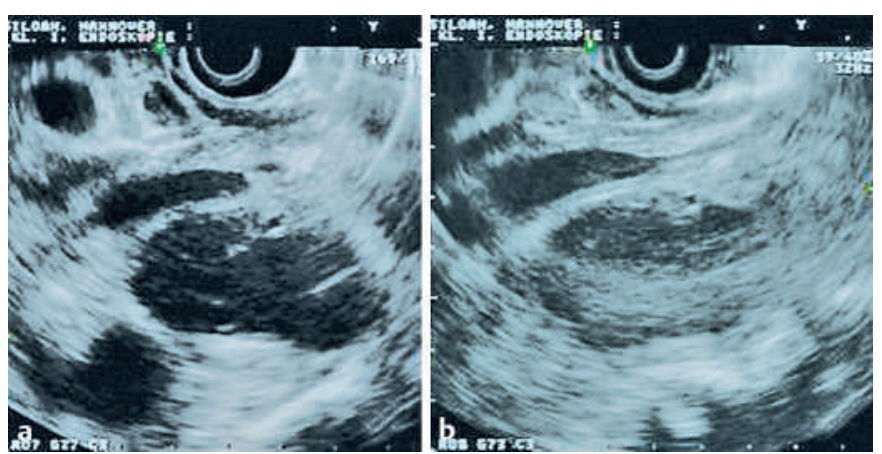

Figure 2 Transduodenal endoscopic ultrasonography (EUS) with the custommade EUS balloon (a) and with the commercially available EUS balloon (b).

balloon to a diameter of $3 \mathrm{~cm}$, and the diameter after the balloon had been held at $3 \mathrm{~cm}$ for $1 \mathrm{~min}$. There were no patients with stenotic tumors.

Application of the commercially available EUS balloons required a mean of $17.1 \mathrm{~s}$ (SD $7.2 \mathrm{~s}$, range 7-29s) and that of custommade balloons required a mean of $46 \mathrm{~s}$ (SD 23, range 22-93 s; $P<0.001$ with Student's $t$ test). The balloon diameter after inflation to a diameter of $3 \mathrm{~cm}$ and holding for $1 \mathrm{~min}$ was $2.8 \mathrm{~cm}$ (SD 0.47, range $1.5-3.0 \mathrm{~cm}$ ) versus $2.7 \mathrm{~cm}$ (SD 0.5 , range $1-3 \mathrm{~cm} ; P=0.55$ ) for commercially available and custom-made balloons, respectively. There were no differences in the time required to inflate the balloons to a diameter of $3 \mathrm{~cm}$ or the time required to remove the balloons. The average examination time was approximately $25 \mathrm{~min}$. The endoscopic image was slightly impaired in one of 10 examinations with the commercially available balloons and in two of 20 examinations carried out with the custom-made balloon. This was due to an overhanging glove finger, and was avoided in subsequent investigations. However, diagnosis was possible in all of the patients examined (Figure $\mathbf{2}$ ). In the custom-made balloon group, 11 patients underwent a diagnostic fine-needle aspiration procedure (five in the pancreas, six in the stomach and mediastinal), seven patients underwent diagnostic biliary EUS, and two patients received pseudocyst drainage.

The cost of one commercial balloon was $€ 13.91$. After purchase of the conical rub- ber-band applicator (€22), one custommade EUS balloon with a rubber band costs $€ 0.37$ per examination. Custommade EUS balloons thus provide an examination quality comparable to that of commercially available EUS balloons at a considerably reduced cost.

In routine clinical use we have encountered an important variability in the thickness of latex glove finger ends even within the same batch of gloves. This was not observed in the series studied, but can lead to artefacts especially where contact pressure is limited (stomach): This can hamper the quality of the EUS picture. An alternative with less latex thickness are latex finger cots that can be fixed in a similar manner as described above.

Endoscopy_UCTN_Code_TTT_1AS_2AG

M. B. Frenz, H. Pauka, A. Riphaus, T. Wehrmann

Dept. of Medicine I, Siloah Hospital, Hanover, Germany.

\section{Corresponding author}

\section{B. Frenz, M.D.}

Dept. of Internal Medicine I

Siloah Hospital

Roesebeckstrasse 15

30449 Hanover

Germany

Fax: $\quad$ +49-511-9272669

Email: mfrenz@doctors.org.uk

DOI: $10.1055 / \mathrm{s}-2006-944901$ 